\title{
From the Editor of Sexuality and Disability: Taking the Lens Cap off the Telescope
}

\author{
Sigmund Hough ${ }^{1}$
}

Published online: 29 April 2015

(C) Springer Science+Business Media New York 2015

The journal of Sexuality and Disability has become a professional home for many and a place of professional rejuvenation for still more. With the intelligence, experience, motivation and commitment from our authors, readership and editorial board; our publishing telescope looks far and wide across the globe for the opportunity to share and discover. Clearly, we must continue this good work.

However, being good and productive is not a place to rest and smile. Being good and productive is a place to launch a new adventure, to find a new discovery and embrace the calling of a new opportunity. Such is the chance for us here.

Taking the lens cap off the telescope means a new look at what is familiar, and realizing the new elements as a part of what had been known. The challenge is simple. Look at life. Look at individuals. Look at the human condition, the politics, laws, and the potential disparity within healthcare. Look at the challenges in living and in life, the tragedies, the wonder and the joy. Looking clearer through the telescope, we now see the day-to-day life events that are a part of the experience for individuals with disabilities/medical conditions and aspects of sexuality. Research and scholarly work gives voice for understanding and change. We will be listening for you.

Sexuality and Disability continues to provide original impact articles addressing the mental health and medical aspects of sexuality in relation to rehabilitation, hospital, academic and community settings, publishing up-to-date articles, case studies, clinical practice reports, reviews, featured articles, historical articles, special grand rounds topics, brief research reports and survey data reports. Value benefit is provided to authors through

Sigmund Hough

Sigmund_Hough@hms.harvard.edu

$1 \quad 100$ Cummings Center, Suite 207, Beverly, MA 01915-6144, USA 
worldwide electronic exposure and professional access, while readership gains from scholarly contributions to advance the field through research, best-practice and educational articles. The refined lens of individual contributions from the local and international community continues to deliver a wealth of information on the topic of sexuality and disability for the reader. Thank you for being a part of our professional network. 